\title{
Pressure sores: a personal comment
}

\author{
J C McGregor BSc MB FRCS FRCS (Ed)
}

Consultant Plastic Surgeon, Bangour General Hospital, West Lothian, Scotland.

Pressure sores have always been with us and remain so. The care and prevention of sores in spinal injuries have shown a dramatic improvement over the past decade while for other categories this cannot be said.

Key words: pressure sores; spinal injuries; non spinal injuries.

\section{Comment}

It has been well known that pressure sores or decubitus ulcers have existed from ancient times and have perplexed as well as vexed physicians and surgeons alike. While it is also established that the prime, if not sole cause of their production is pressure acting for a surprisingly short period of time in susceptible individuals, prevention, treatment and even recognition of them remains a taxing and expensive problem. To those of us who work with patients who are at particular risk, such as those with a spinal injury, the occurrence of a pressure sore under our supervision represents a very serious breakdown in care and should be rare. The situation outwith a specialist unit remains particularly disappointing, and, in spite of continued attempts at educating by lectures and publications in non specialist journals, pressure sores still occur in significant numbers. In some cases they seem even to be totally unexpected and misunderstood by the medical and nursing staff. Resentment is likely if it is inferred that the cause of the pressure sore lies in a failure in the system of care-but this is usually always the fact of the matter.

When I was first appointed a consultant in 1980 , surgery for the treatment of pressure sores in spinal injuries units appeared to have been a rather uncertain and slow process. Over the previous periods, any skin flaps that were done were transposition or rotation random pattern flaps. These had a precarious blood supply, limited mobility, and required optimal bacteriological conditions to ensure good healing. A revolution occurred with the development of musculo- cutaneous flaps in reconstructive surgery in the 1980s following various publications (including that of NAHAI et al relating to the tensor fascia latae musculocutaneous flap for pressure sore repair). Now it was possible to utilise a greatly improved blood supply, mobility, and cavity filling abilities to obtain rapid and more secure repairs than had been previously obtained. ${ }^{2-5}$ Not everyone was convinced that even these glorious new flaps were the final solution and there were critics.

This author well remembers a particularly bitter open exchange with a British colleague at a European paraplegic international meeting held in Mulhouse in 1979. It was his strongly held view that 'the solution' to pressure sores lay with medical not surgical methods, especially not the new flaps. In fact, of course, he was partly correct in that the education of patients and nursing staff alike is of prime importance.

Without this, no flap repair in the world can guarantee that there will not be a recurrence of previous sores.

With this in mind and to help in the overall management of spinal injuries skin problems, a nurse coordinator was appointed to the Spinal Unit, Edenhall Hospital during the 1980s. Her job was based in the hospital but close liaison with patients in the community and with the district nurses enabled early expert advice to be given on overall care. As a result, over the past 5 years there has been a marked reduction in the number of patients admitted with pressure sores to and requiring surgery in this unit. This has almost made my services 
redundant! A further factor in the overall improvement has been the increased use and availability of support surfaces and special beds (such as low air-loss) both for inpatients as well as outpatients.

Unfortunately, the same dramatic reduction cannot be seen in the non spinal injuried patients, notably those suffering from disseminated sclerosis, rheumatoid arthritis, and spina bifida. ${ }^{6}$ Not only are there restricted inpatient facilities, but community care and backup services are grossly inadequate.

A recent review of pressure sores treated in the Bangour Hospital Plastic Unit over the past 10 years (mainly non spinal injuries), showed an increase in cases occurring in certain groups such as those with rheumatoid arthritis, spina bifida, and disseminated sclerosis compared to the preceding 10 years. Though an increased use of musculocutaneous flaps had not (as anticipated) resulted in an increased rate of patient turnover, a reduced rate of pressure sore recurrence was demonstrable. ${ }^{7}$ This is a promising observation which proves that the contribution of surgery is not insignificant. The total number of pressure sores in patients in hospitals and elsewhere are unknown, as is the total cost of treatmentbut it must be considerable. It is gratifying that at least the care of those in our spinal units has been substantially improved over the past 20 years and has almost certainly been extremely cost effective. Sir Ludwig Guttmann would surely have approved had he been present today, but would he be satisfied that the problem has been solved or completely understood?

Though it is true that those involved with the publication of this journal - Paraplegia editors and the board, and contributors have and are working very hard, and have been successful in advancing the care and prevention of pressure sores in patients, there is still much to be done. This journal is probably not read by general practitioners, district nurses, or other surgical and medical specialists many of whom also have to look after patients at risk.

Education of and more widespread publication and information directed towards these persons are essential. I would encourage all of you who are involved in the care of paraplegic and non paraplegic patients at risk to think of ways whereby this can be achieved. The example of what has now been obtained for paraplegic patients should be an added stimulus for both teachers and pupils.

\section{Acknowledgements}

I would like to thank $\mathrm{Mr}$ A C Buchan and $\mathrm{Mr}$ Peter Edmond for their personal advice and encouragement in my work in both units and for their own invaluable contribution to the care of spinal injuries. Mrs Fay Mackay kindly typed the script.

\section{References}

1 Nahai F, Silverton JS, Hill HL, Vasconez LO (1978) The tensor fasciae data musculo-cutaneous flap. Ann Plast Surg 1: 372-379.

2 McGregor JC, Buchan AC (1980) The tensor fasciae latae flap and its use in the closure of trochanteric and ischial pressure sores. Paraplegia 18: 301-305.

3 McGregor JC, Buchan AC, Watson ACH (1980) Musculo-cutaneous flaps in reconstructive surgery. J R Coll Surg Edinb 25: 400-414.

4 McGregor JC (1982) The Gracilis musculocutaneous flap as a method of closure of ischial pressure sores. Paraplegia 20: 217-226.

5 McGregor JC (1983) The reverse latissimus dorsi musculo-cutaneous flap. J R Coll Surg Edinb 28: 154-156.

6 Wylie FJ, McLean NR, McGregor JC (1984) The problem of pressure sores in a regional plastic surgery unit. J R Coll Surg Edinb 29: 38-43.

$7 \mathrm{McGregor}$ JC, Hoogbergen MM (in press) An audit of pressure sores treated in a regional plastic surgery unit (1971-1990), JR Coll Surg Edinb. 